KLEINE TEXTE FƯR THEOLOGISCHE VORLESUNGEN UND UBUNGEN

HERAUSGEGEBEN VON HANS LIETZMANN

$24 / 25$

\title{
MARTIN LUTHERS GEISTLICHE LIEDER
}

HERAUSGEGEBEN

voN

ALBERT LEITZMANN

PREIS o,6o MARK

BONN

A. MARCUS UND E. WEBER'S VERLAG 1907 
